\title{
Research on Evaluation Method of Cost Management and Control Effect of Power Transmission and Transformation Project Based on BIM Technology
}

\author{
Zhang Duo ${ }^{1}$, Wang Zhengping ${ }^{1}$, Yin Chenlei ${ }^{1, *}$ \\ ${ }^{1}$ State Grid Hebei Electric Power Co., Ltd. Hengshui Power Supply Company, Hengshui, Hebei, China
}

\begin{abstract}
The power transmission and transformation project is the carrier of power energy transmission and plays an important role in supporting economic development and improving people's living standards. Based on the application status of BIM technology and the actual situation in power transmission and transformation projects, this paper combs the application fields of BIM technology from the perspective of the whole process of project construction, and constructs an index system based on the construction effect of the whole process of the project. The analytic hierarchy process is used to calculate the index weights, and the expert scoring method is used to evaluate the effects of different projects according to the actual situation, so as to enhance the application scope of BIM technology in the construction of power transmission and transformation projects. The research results of this paper can provide support and reference for the establishment of a construction digital model covering the entire process and resources of a power project, and a BIM system suitable for the power industry.
\end{abstract}

\section{Introduction}

BIM (Building Information Modeling) has been continuously applied in some foreign projects in recent years, and its direct economic and social benefits have become increasingly obvious. This technology is a method and technology to manage and optimize the entire process of design and construction of projects under construction by integrating and extracting data such as geometric attributes, physical properties, and material properties of engineering projects, creating and using analog digital models.

Literature [1] analyzed the factors of the early stage cost management of power grid construction projects, established a comprehensive evaluation index system for the early stage cost management of power grid construction projects, constructed a fuzzy comprehensive evaluation model based on the entropy method, and combined with empirical analysis to verify the effectiveness of the model. Literature [2] first analyzes the suitability of BIM technology in power grid project cost management; then from the perspective of the whole process management, it studies the cost of BIM technology in the five stages of power grid project decision-making, design, bidding, construction, and completion. Management application mode; finally, from policy guidance, industry standards, BIM platform construction, BIM talent training, four aspects of BIM technology application recommendations in power grid project cost management are put forward. Literature [3] analyzed the application mode and implementation difficulties of BIM technology in power engineering cost management, combined with actual cases, and put forward relevant suggestions for promoting the application of BIM technology in power engineering cost. Literature [3] cuts in from the application points of BIM model, design management, construction management, schedule management, etc., to study the effect and significance of BIM technology on power grid engineering construction.

To sum up, the current related scholars pay more attention to the application of BIM technology in the construction process of power transmission and transformation projects for research, but the evaluation and analysis of the effect of BIM technology cost control are relatively lacking. Therefore, this article combines the division of power transmission and transformation project construction management stages, analyzes the application scenarios of BIM technology in different management stages, and builds an evaluation model based on the analytic hierarchy process on this basis to guide grid companies to efficiently promote and apply BIM technology.

\section{Analysis of application scenarios of BIM technology in power transmission and transformation projects}

The construction process of power transmission and transformation projects can be roughly divided into five stages: decision-making stage, design stage, bidding stage, construction stage and completion settlement stage. The 
main role of BIM technology in each stage of the construction and implementation of power transmission and transformation projects is shown in the following figure 1 .

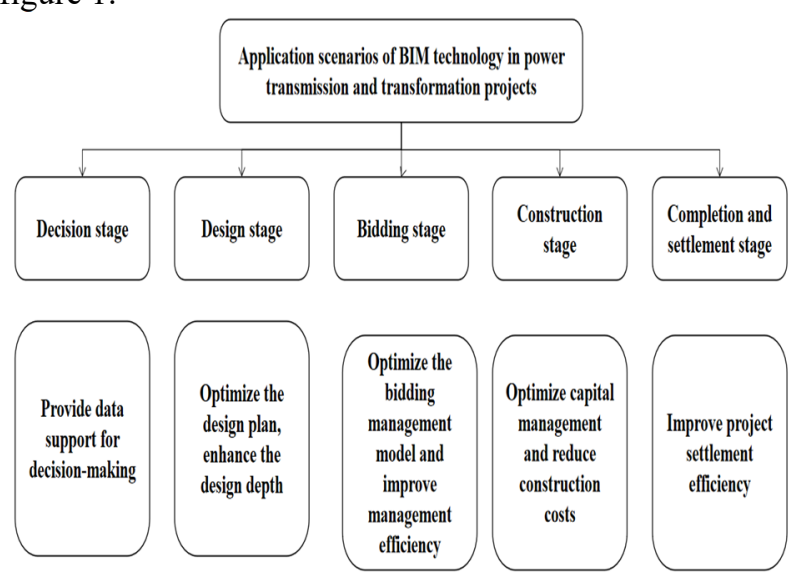

Figure 1. The main role of BIM technology application in various stages of power transmission and transformation project construction.

\subsection{Application of BIM in the decision-making stage of power transmission and transformation projects}

Using the BIM model in the decision-making phase can retrieve information on the cost of completed projects similar to the project, and can provide reliable data support for the cost of the project, thereby greatly improving the accuracy and efficiency of the project cost.

\subsection{Application of BIM in the design stage of power transmission and transformation projects}

By applying the collision check function of the BIM system, the drawings transmitted on the information platform are summarized, which is beneficial for the designers to review the drawings as a whole. At the same time, BIM has a three-dimensional visualization function, as well as $3 \mathrm{D}, 4 \mathrm{D}$ or $5 \mathrm{D}$ view functions, making it easier to find problems in collision inspection, so as to quickly and effectively solve design problems, reduce rework due to design problems during construction, and reduce costs.

\subsection{Application of BIM in the bidding stage of power transmission and transformation projects}

The BIM system is used in the bidding stage, and the information sharing platform can be used to understand the approximate budget of similar projects, and the price system of the location of the project construction can be used to obtain all the budgets required for each link of the project, thereby obtaining the initial budget of the overall project. At the same time, the bidding party can also use the BIM system to package and send its own project budget to each bidder, which can make the bidding information more integrated and consistent.

\subsection{Application of BIM in the construction phase of power transmission and transformation projects}

Using the BIM system in the construction phase of the project can well control all aspects of the cost, and grasp the determination and payment of the project progress payment and project change claims. In the phase of project payment, BIM technology can effectively match the time node with the building components. From the actual construction process, the actual construction situation and entry are dynamically updated in the system, and the Internet is used to share information in real time. In this way, it is possible to macroscopically understand the current total construction volume of all construction parties at a specific time node, and form a project meter, so that different construction units can be monitored separately. At the same time, the construction party can also settle the project payment according to the project progress in the system.

The application of BIM technology can change the link between the determination and payment of the claim fee and verify the relevant basis for the reasonableness of the claim. Utilizing the unity of information in the BIM model, the system will automatically make real-time changes when the quantity of work changes, while retaining the traces of the changes, so that both the construction unit and the investment unit can clearly obtain the quantity information in the BIM system. Provide strong data support for changing costs.

\subsection{Application of BIM in the completion and settlement stage of power transmission and transformation projects}

In the completion and settlement link, because the BIM model has clear information records for all building components, such as project progress information, material price information, project payment information, project quantity information, and so on. Each module containing this information will be dynamically updated according to the progress of the project until the completion of the project. Therefore, the use of the BIM model can make it easier to improve processing efficiency during project completion and settlement, and safeguard the interests of both parties, so that completion settlement will not be shelved due to accounting problems, which effectively saves both parties a lot of time and cost.

\section{Construction of the evaluation system for the cost control effect of power transmission and transformation projects based on BIM technology}

BIM not only changes the way of design, planning, and construction, but also provides a way to operate a building after it is completed. The use value of BIM in the operation phase of a building was quickly discovered by related industries. Owners also found that using BIM can reduce construction costs and improve asset management. BIM technology has proven to be the most invaluable resource 
for managers. The BIM management of the whole life cycle allows all participants to obtain equal and timely information, and greatly reduces the construction time and cost in all life stages of the project.

\subsection{Construction of the evaluation index system}

Combining the actual application of BIM technology at each stage of the life cycle, divide each stage, and combine the key points of cost control to build an index system, as shown in Table 1 below.

Table 1. Evaluation index system.

\begin{tabular}{|c|c|}
\hline Evaluation field & Index \\
\hline $\begin{array}{l}\text { Decision stage } \\
\text { effect }\end{array}$ & $\begin{array}{l}\text { Feasibility study estimation } \\
\text { accuracy }\end{array}$ \\
\hline $\begin{array}{l}\text { Design stage } \\
\text { effect }\end{array}$ & $\begin{array}{c}\text { Design engineering } \\
\text { accuracy }\end{array}$ \\
\hline $\begin{array}{l}\text { Construction } \\
\text { stage effect }\end{array}$ & $\begin{array}{c}\text { Timeliness of project } \\
\text { progress } \\
\text { Claim visa norms }\end{array}$ \\
\hline $\begin{array}{c}\text { Settlement stage } \\
\text { effect }\end{array}$ & $\begin{array}{l}\text { Completion settlement } \\
\text { efficiency level }\end{array}$ \\
\hline
\end{tabular}

\subsection{Evaluation method model construction}

(1) Basic principles of analytic hierarchy process The index weights are determined by the analytic hierarchy process, and a pairwise comparison judgment matrix table of indicators at each level is constructed. Because this evaluation model is highly subjective, 10 experts who have participated in the project and have rich engineering experience are invited to perform the evaluation of the indicators. Two comparisons and judgments, take the average of the scores of the experts, and get the weight of each indicator.

(2) Expert scoring rules

Analyze the application of BIM in the project, combine expert experience and actual engineering data to score the effect, and finally form a comprehensive scoring level for each project. In order to compare and analyze the actual effect of BIM technology on cost control in different projects, explore advanced experience, and provide support and reference for the better use of BIM technology. According to the actual situation of cost control, an evaluation index system is constructed, and each index is further refined and divided. Each evaluation index is divided into 5 evaluation levels, and the number 1-5 indicates that the control effect is gradually increasing. Among them, the feasibility study estimate and the accuracy of the engineering quantity are all based on the actual settlement data as the object of comparison and analysis. The timeliness of progress and the standardization of the claim visa are based on the actual project construction process management as the evaluation support and basis. The level of settlement efficiency is the basis for comparison and analysis with that before the adoption of BIM technology.

\subsection{Empirical analysis}

Six projects that have been constructed and completed in a certain area are selected as the empirical analysis objects, combined with the above-mentioned method and theoretical model, to carry out the evaluation of the application effect of BIM technology in different projects. Combine the analytic hierarchy process to calculate the weight. The weight is the quantification of the importance of the index, and the determination of the index weight is the process of analyzing the importance of each index and determining its weight. The greater the weight, the greater the importance, and vice versa, the smaller. There are many ways to determine the weight. The analytic hierarchy process has the advantages of clear hierarchy, clear regulations, low data accuracy requirements and more accurate results, so the analytic hierarchy process is used to determine the weight. The main steps are as follows:

(1) Establish a hierarchical analysis structure model: establish a hierarchical structure diagram according to the actual situation and establish a clear hierarchical analysis index system.

(2) Constructing the judgment matrix: For the factors of the same layer that are subordinate to (or affect) each factor of the upper layer, use the pairwise comparison method and the 1-9 comparison scale to construct the judgment matrix A.

$$
A=\left(\begin{array}{cccc}
a_{11} & a_{12} & \cdots & a_{13} \\
a_{21} & a_{22} & \cdots & a_{23} \\
\vdots & \vdots & \cdots & \vdots \\
a_{n 1} & a_{n 2} & \cdots & a_{n n}
\end{array}\right)
$$

Among them: $a_{i j}>0, a_{i j}=1, \quad a_{i j}>0=1 / a_{j i}$. The calculation results are shown below.

Table 2. Index weight calculation.

\begin{tabular}{ccc}
\hline $\begin{array}{c}\text { Evaluation } \\
\text { field }\end{array}$ & Index & Weights \\
\hline $\begin{array}{c}\text { Decision } \\
\text { stage effect }\end{array}$ & $\begin{array}{c}\text { Feasibility study } \\
\text { estimation } \\
\text { accuracy } \\
\text { Design } \\
\text { Design stage } \\
\text { effect }\end{array}$ & $\begin{array}{c}\text { engineering } \\
\text { accuracy } \\
\text { Timeliness of }\end{array}$ \\
$\begin{array}{c}\text { Construction } \\
\text { stage effect }\end{array}$ & $\begin{array}{c}\text { project progress } \\
\text { Claim visa norms } \\
\text { Completion } \\
\text { settlement } \\
\text { Settlement }\end{array}$ & 0.21 \\
stage effect & 0.18 \\
\hline
\end{tabular}

Combining the experts and the actual settlement status of the project, construction status, etc., scored the cost control status of the 6 projects, and calculated the following results on average. 
Table 3. Empirical data table.

\begin{tabular}{ccccccc}
\hline Index & Project A & Project B & Project C & Project D & Project E & Project F \\
\hline $\begin{array}{c}\text { Feasibility study } \\
\text { estimation accuracy }\end{array}$ & 4.65 & 3.98 & 4.21 & 4.68 & 4.53 & 3.67 \\
$\begin{array}{c}\text { Design engineering } \\
\text { accuracy }\end{array}$ & 3.87 & 4.19 & 4.22 & 4.48 & 4.31 & 3.88 \\
$\begin{array}{c}\text { Timeliness of project } \\
\text { progress }\end{array}$ & 4.12 & 4.75 & 4.58 & 4.19 & 4.66 & 4.75 \\
$\begin{array}{c}\text { Claim visa norms } \\
\text { Completion settlement } \\
\text { efficiency level }\end{array}$ & 3.95 & 4.54 & 4.74 & 4.01 & 3.90 & 4.91 \\
\hline
\end{tabular}

Comprehensive weight calculation results and expert scoring results to obtain the cost control effect score of

each project is as follows.

Table 4. Comprehensive evaluation results.

\begin{tabular}{ccccccc}
\hline Index & Project A & Project B & Project C & Project D & Project E & Project F \\
\hline $\begin{array}{c}\text { Comprehensive } \\
\text { results }\end{array}$ & 4.237 & 4.275 & 4.258 & 4.245 & 4.409 & 4.345 \\
\hline
\end{tabular}

It can be seen from the evaluation results that the overall control effect of the $\mathrm{E}$ project is more prominent.

\section{Conclusion}

This paper constructs an evaluation model for the cost control effect of BIM technology in power transmission and transformation projects, which can effectively guide power grid companies to promote and apply BIM technology.

\section{References}

1. Zhang Jin. Research on the Early Stage Cost Management Evaluation System of BJ Company Power Grid Construction Project[D]. Xi'an University of Science and Technology, 2019.

2. Liu Hongzhi, Tu Qingbo, Gao Jingren, Li Yan. Research on the application mode of power grid project cost management based on BIM technology[J]. Shaanxi Electric Power, 2016, 44(11): 66-71.

3. Wang Quan, Zhang Yufeng. Analysis of the application of building information modeling (BIM) in power engineering cost[J]. Journal of Wuhan University (Engineering Edition), 2018, 51(S1): 380386.

4. Ke Zihuan, Gao Laixian. Research on the application of BIM technology in the construction of power grid projects [J]. China Standardization, 2019(14): 7072.4. Conclusion 